Check for updates

Cite this: RSC Adv., 2017, 7, 32528

Received 4th April 2017

Accepted 5th June 2017

DOI: $10.1039 / c 7 r a 03849 f$

rsc.li/rsc-advances

\section{Nanoplate-assembled hierarchical cake-like ZnO microstructures: solvothermal synthesis, characterization and photocatalytic properties}

\author{
Miao Wang, (D) *a Zhongchao Jin, ${ }^{a}$ Mengjie Liu, ${ }^{a}$ Guoqing Jiang, ${ }^{\text {*a }}$ Hongbin Lu, ${ }^{\mathrm{b}}$ \\ Qiuxiang Zhang, ${ }^{\mathrm{b}}$ Jianfeng Ju $\mathrm{u}^{\mathrm{a}}$ and Yanfeng Tang ${ }^{\mathrm{a}}$
}

Employing $\mathrm{NH}_{4} \mathrm{BF}_{4}$ as a fluoride source, novel hierarchical cake-like $\mathrm{ZnO}$ microstructures have been fabricated by a simple, template-free, environmentally-friendly DMF ( $N, N$-dimethylformamide)-mediated solvothermal route. The products were characterized by XRD, SEM, TEM and nitrogen adsorptiondesorption and PL. The SEM and TEM results indicated that the hierarchical cake-like ZnO were assembled from numerous tiny nanoplates. DMF acted as solvent and structure-directing agent to guide the formation of $\mathrm{ZnO}$ nuclei and the self-assembled preferential growth from smaller building units (nanoplates) to larger cake-like $\mathrm{ZnO}$ microstructures. The as-prepared samples, $\mathrm{ZnO}$ or $\mathrm{ZnOHF}$ could be regulated by altering the two major reaction parameters (the amount of DMF and fluoride source). Timedependent morphological evolution results revealed that self-assembly and Ostwald ripening were the main formation mechanism for the hierarchical $\mathrm{ZnO}$ microstructure. Furthermore, the photocatalytic activity of the as-prepared $\mathrm{ZnO}$ samples was evaluated by the degradation of Rhodamine $\mathrm{B}(\mathrm{RhB})$ under UV light irradiation. Such hierarchical cake-like ZnO microstructures showed an excellent photocatalytic activity. Additionally, the cake-like ZnO microstructures were chemically stable, and the efficiency remained almost the same after being recycled five times.

\section{Introduction}

In the past decade, hierarchical architectures have been a hot topic in chemistry and materials science for their wide applications in catalysis, sensors, optics, etc. ${ }^{1-4}$ Hence, the controlling synthesis of hierarchical morphologies is of great interest and importance to investigate their applications related to morphology. So far, various hierarchical structures have been prepared by the self-assembly of low-dimensional nanoscaled units using structure directing agents such as surfactants, polymers, and organic molecules. ${ }^{5-8}$ However, the directing agents used during the synthesis procedures are difficult to completely remove from the surfaces of the synthesized products. Therefore, the development of mild, template-free and green methods to produce hierarchical architectures is still an ongoing demand for practical applications.

As known, various semiconductors have been widely used to solve energy and environment problems due to their excellent photocatalytic properties. As the most extensively studied semiconductor, $\mathrm{ZnO}$ has been investigated intensively as photocatalysts because of its appropriate band gap (3.37 eV), low cost, non-toxicity high quantum yields and high stability. ${ }^{8-10}$

${ }^{a}$ College of Chemistry and Chemical Engineering, Nantong University, Nantong 226019, P. R. China.E-mail: hi_wangmiao@163.com;jgq3518@163.com

${ }^{b}$ Institute of Materials Engineering, Nanjing University, Nantong 226019, P. R. China
Nevertheless, its low photocatalytic efficiency has been still recognized as a major obstacle for the degradation treatments of pollutants. Generally, compared with conventional nanocrystallites, complicated hierarchical ZnO micro/ nanostructured photocatalysts are highly desired because of their unique physicochemical properties. With a view to improving the photocatalytic activity, hierarchical architectures possess large surface area, porous structures, enhanced light harvesting and more active sites, making themselves feasible to contact the reactants and transport organic pollutants. ${ }^{11-14}$ Therefore, much work has been devoted to exploring and fabricating $\mathrm{ZnO}$ with hierarchical architectures to achieve novel or enhanced photocatalytic efficiency, consequently, a variety of hierarchical ZnO micro/nanostructures have been successfully synthesized based on chemical procedure. ${ }^{15-25}$ However, the facile template-free synthesis technologies which could be highly efficient and environmentally benign for the construction of hierarchical $\mathrm{ZnO}$ micro/nanostructures are still necessarily required. In previous work, we have explored the hierarchical flower-like ZnOHF nanostructures via a precipitation reaction between $\mathrm{ZnSO}_{4} \cdot 7 \mathrm{H}_{2} \mathrm{O}$ and $\left(\mathrm{NH}_{4}\right)_{2} \mathrm{SiF}_{6}$ or $\mathrm{NH}_{4} \mathrm{BF}_{4} \cdot{ }^{1,26,27}$ In this work, using a mixture of DMF and water as the solvent, we proposed a facile, one-step and template-free solvothermal route for the synthesis of $3 \mathrm{D}$ cake-like $\mathrm{ZnO}$ microstructures which was assembled from $2 \mathrm{D} \mathrm{ZnO}$ ultrathin nanoplates. To the best of our knowledge, there has been no 
report on the preparation of such hierarchical cake-like $\mathrm{ZnO}$ microstructures. Employing $\mathrm{NH}_{4} \mathrm{BF}_{4}$ as fluoride source, this DMF-mediated solvothermal route is a simple (only one-step procedure), greener (not using HF or further calcination) and more controllable approach to prepare hierarchical ZnO. Excellent photodegradation performance was obtained due to the large surface area and unique nanoplates-assembled 3D cake-like structures.

\section{Experimental section}

\section{Synthesis of hierarchical cake-like ZnO microstructures}

All chemicals including $\mathrm{ZnSO}_{4} \cdot 7 \mathrm{H}_{2} \mathrm{O}, \mathrm{NH}_{4} \mathrm{BF}_{4}$, and DMF were A. R. grade and used directly without any treatment. Distilled water was used throughout. In a typical experiment, the synthesis of hierarchical cake-like $\mathrm{ZnO}$ microstructures was described in detail as follows. $5 \mathrm{~mL}$ of distilled water was diluted to $20 \mathrm{~mL}$ DMF to form solution. $1 \mathrm{mmol} \mathrm{ZnSO}_{4} \cdot 7 \mathrm{H}_{2} \mathrm{O}$ was added to the solution and stirred at room temperature for $30 \mathrm{~min}$, followed by the addition of $0.5 \mathrm{mmol} \mathrm{NH}_{4} \mathrm{BF}_{4}$. The stirring was continued for another $30 \mathrm{~min}$. Then, the resulting suspension was transferred into a $30 \mathrm{~mL}$ Teflon flask held in a stainless steel autoclave, and the autoclave was sealed and heated at $120{ }^{\circ} \mathrm{C}$ for $24 \mathrm{~h}$ in an oven. After the autoclave was gradually cooled to room temperature, the resulting white product was precipitated by centrifugation, washed with distilled water and ethanol and finally dried at $70{ }^{\circ} \mathrm{C}$. For a systematic study, a series of experiments with different reaction time, molar ratio of starting materials and the amount of DMF (the total volume of distilled water and DMF was $25 \mathrm{~mL}$ ) were also conducted under similar conditions, respectively.

\section{Characterization}

The crystalline phases of the products were analyzed by XRD on a Bruker D8-Advance powder X-ray diffractometer $(\mathrm{Cu} \mathrm{K} \alpha$ radiation $\lambda=0.15418 \mathrm{~nm}$ ). The morphologies and microstructures of the samples were studied by scanning electron microscopy (SEM, Hitachi S-4800) employing an operating voltage of $15 \mathrm{kV}$ and transmission electron microscopy (TEM, JEOL-2100F) under $200 \mathrm{kV}$ accelerating voltage. Nitrogen adsorptiondesorption isotherms were collected using a Micromeritics ASAP 2020C apparatus and the specific surface area was calculated using the Brunauer-Emmett-Teller (BET) method. The photoluminescent (PL) spectra of the samples were recorded on HITACHI F-7000 spectrophotometer at room temperature.

\section{Measurement of photocatalytic activity}

The photocatalytic activity of the as-prepared $\mathrm{ZnO}$ was evaluated by photocatalytic decolorization of RhB aqueous solution. A $250 \mathrm{~W}$ high-pressure mercury $\operatorname{lamp}(\lambda=365 \mathrm{~nm})$ was used as the light source and an electric fan and cycled condensate water were used to prevent thermal catalytic effects. The suspension was vigorously stirred during the process and the temperature of suspension was maintained at $20 \pm 2{ }^{\circ} \mathrm{C}$. Typically, $30 \mathrm{mg}$ of the as-prepared $\mathrm{ZnO}$ was added to $50 \mathrm{~mL}$ of the $\mathrm{RhB}\left(20 \mathrm{mg} \mathrm{L}^{-1}\right)$ solution. Before lamp was turned on, the solution was continuously stirred for 30 min in dark to reach an adsorptiondesorption equilibrium. Then, the solutions were irradiated by $\mathrm{Hg}$ lamp under magnetic stirring. During irradiation, $3.5 \mathrm{~mL}$ of the suspension was continually taken from the reactor at given time intervals. Finally, the photocatalyst powders and the pollutions solution were separated using a centrifugal machine. The concentrations of RhB solutions were determined through Shimadzu UV-2401PC spectrophotometer.

\section{Results and discussion}

\section{Crystalline structure, morphology and surface areas of hierarchical cake-like ZnO}

The crystallographic structure of the as-prepared $\mathrm{ZnO}$ samples were confirmed by XRD, as shown in Fig. 1a. It can be observed that the peaks appearing in all of the spectra are unambiguously indexed to hexagonal wurtzite ZnO (JCPDS card no. 36-1451). No additional peaks are detected in the XRD patterns, confirming that the obtained samples are single phase and consequently of very high purity. While other reaction conditions were kept identical, the XRD patterns of the products obtained from $12 \mathrm{~h}$ and $3 \mathrm{~h}$ are shown in Fig. $1 \mathrm{~b}$ and c, respectively. The diffraction peaks can also be indexed as hexagonal phase of $\mathrm{ZnO}$, revealing that reaction time has no obvious effect on the crystalline phase of the products. However, the XRD patterns of the samples obtained from $3 \mathrm{~h}$ and $12 \mathrm{~h}$ show lower diffraction peaks than those of $24 \mathrm{~h}$, indicating the enhancement of the crystallinity of the product or the increase of particle size with the prolongation of the reaction time.

The morphology and size of the 3D hierarchical cake-like ZnO microstructures were characterized by SEM and TEM. The general overview SEM image (Fig. 2a) shows that the panoramic morphology of the as-prepared $\mathrm{ZnO}$ is a $3 \mathrm{D}$ cake-like architecture with rough surface. The diameter of the cake-like microstructure is in the range of $4-6 \mu \mathrm{m}$, and the thickness is about 2-3 $\mu \mathrm{m}$. The high-magnification SEM images (Fig. 2b and c) observed from the front and side view reveal that this cakelike microstructure is a hierarchical structure with nanoplates ordered stacking. The characteristics of the hierarchical cake-

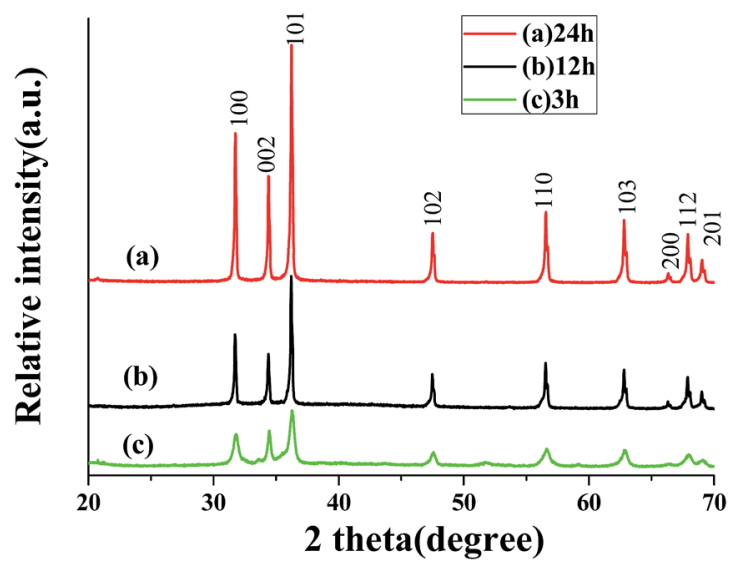

Fig. 1 XRD patterns of the products obtained from different reaction time: (a) $24 \mathrm{~h}$; (b) $12 \mathrm{~h}$; (c) $3 \mathrm{~h}$. 


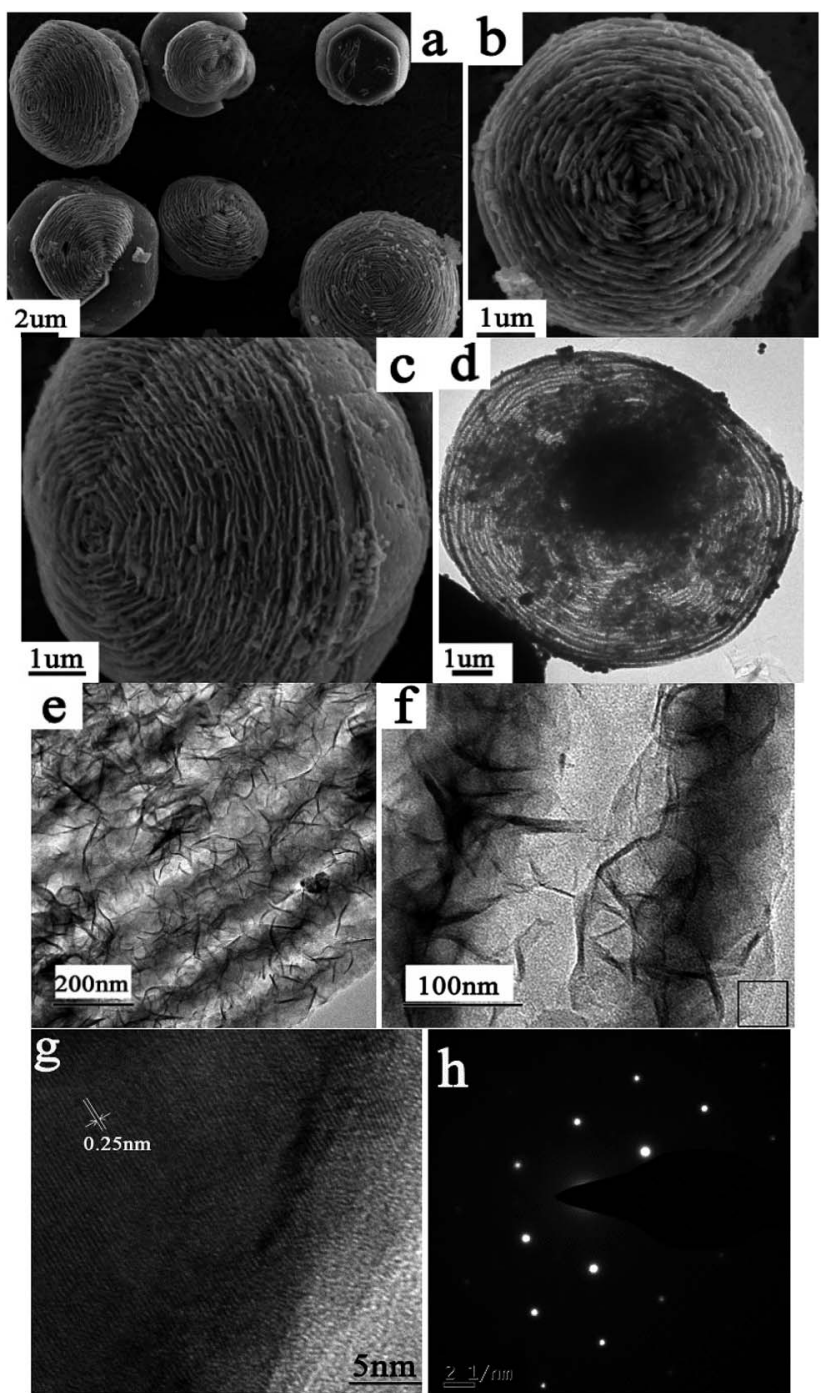

Fig. 2 SEM (a-c), TEM (c-f), HRTEM ( $g$ ) and SAED (h) images of the $\mathrm{ZnO}$ obtained in the typical process.

like structure can be observed more clearly from the TEM images of the products. As shown in Fig. 2d, the hierarchical cake-like microstructures exhibit as novel shape like a fingerprint under the electric beam which consists of a series of concentric rings. TEM images (Fig. 2e) reveal that there is a strong contrast difference between the two neighboring rings. The close-up view (Fig. 2f) further demonstrates that the concentric rings are separated layers and that there are large void spaces among them. Actually, the 3D hierarchical cake-like structure is composed of many thin nanoplates. These nanoplates are oriented overlapping to each other to form the ordered stacking like a layer, which is consistent with the results obtained from SEM (Fig. $2 b$ and c). A representative HRTEM image at the edge of cake-like architecture (marked in Fig. 2f) is shown in Fig. $2 \mathrm{~g}$. The lattice fringes are clearly visible with a spacing of $0.25 \mathrm{~nm}$, which agrees well with the lattice spacing of (101) crystal planes. The SAED pattern (Fig. 2h) recorded on the same part proves the single-crystalline nature, which further supports the claim of crystallinity of $\mathrm{ZnO}$. As far as we know, little work has been conducted on hierarchical cake-like $\mathrm{ZnO}$ microstructures assembled by nanoplates. Due to possessing more surface areas, exposed facets and reactive sites, this unique morphology may be advantageous for facilitating transport of organic pollutants and thus promoting the photocatalytic efficiency.

$\mathrm{N}_{2}$ adsorption-desorption experiment was carried out to characterize the specific surface area of the hierarchical cakelike $\mathrm{ZnO}$ microstructures. Fig. 3 shows the $\mathrm{N}_{2}$ adsorptiondesorption isotherm of the as-prepared hierarchical cake-like ZnO architectures. The isotherm displays a well-defined IV isotherm assigned to the typical $\mathrm{H} 3$ hysteresis loop in the region of $0.6<P / P_{0}<1.0$, suggesting that hierarchical cake-like $\mathrm{ZnO}$ is mesoporous materials, which is consistent with the results of SEM and TEM. The BET surface area of the hierarchical cakelike $\mathrm{ZnO}$ architectures is $113.896 \mathrm{~m}^{2} \mathrm{~g}^{-1}$.

\section{Influences of reaction parameters}

A series of controlled experiments were carried out to investigate the effects of DMF on the formation of hierarchical $\mathrm{ZnO}$ architectures. Similar procedures were performed under the same reaction condition except using the different mixed solutions with different ratios of DMF to water ( $5 \mathrm{~mL} \mathrm{DMF} / 20$ $\mathrm{mL} \mathrm{H}_{2} \mathrm{O}$ or $12.5 \mathrm{~mL} \mathrm{DMF} / 12.5 \mathrm{~mL} \mathrm{H}_{2} \mathrm{O}$ ) instead of the previous solution (20 mL DMF/5 $\mathrm{mL} \mathrm{H}_{2} \mathrm{O}$ ), respectively. The XRD patterns of the as-prepared products are shown in Fig. 4. When the distilled water was used as the only solvent in the absence of DMF, the XRD patterns of the product changed obviously (Fig. 4a), as revealed in our previous work. ${ }^{27}$ All of the diffraction peaks can be indexed to the orthorhombic phase of ZnOHF (JCPDS card no. 74-1816). Similarly, pure ZnOHF were obtained in the mixed aqueous solutions of $5 \mathrm{~mL} \mathrm{DMF} / 20 \mathrm{~mL}$ $\mathrm{H}_{2} \mathrm{O}$ and $12.5 \mathrm{~mL} \mathrm{DMF} / 12.5 \mathrm{~mL} \mathrm{H}_{2} \mathrm{O}$ (Fig. $4 \mathrm{~b}$ and c), no trace of impurities and other phases were observed. Comparatively, pure hexagonal phase of $\mathrm{ZnO}$ were prepared when the solvent was pure DMF (Fig. 4e). Therefore, the amount of DMF plays a crucial role in the formation of $\mathrm{ZnO}$ or $\mathrm{ZnOHF}$.

The corresponding SEM images of the products are listed in Fig. 5a-e, which was obtained from the mixed solvents with the

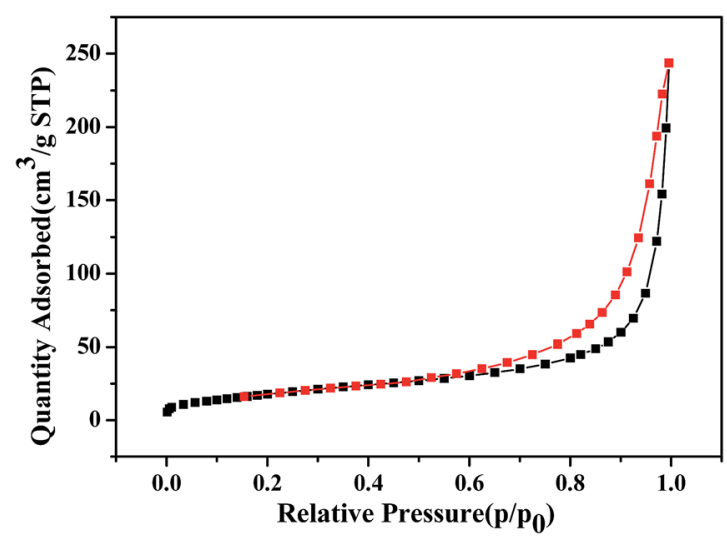

Fig. $3 \quad \mathrm{~N}_{2}$ adsorption-desorption isotherm of hierarchical cake-like $\mathrm{ZnO}$ microstructures. 


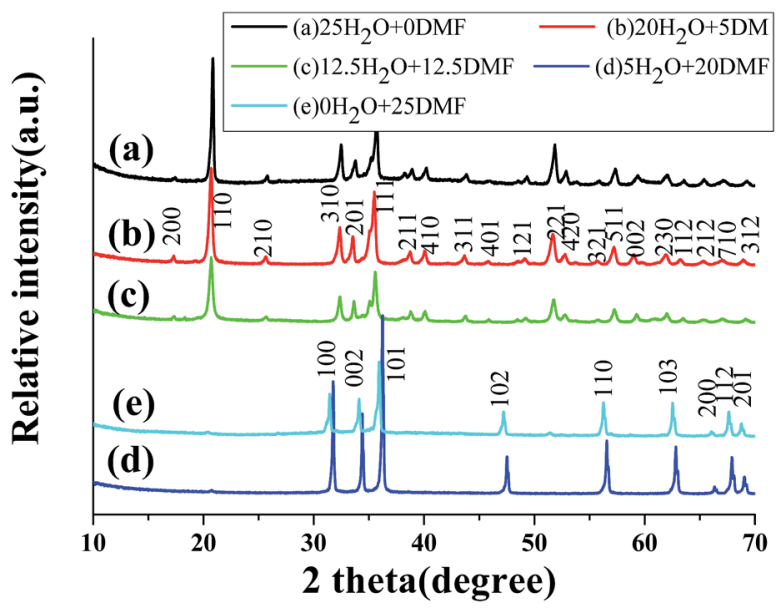

Fig. 4 XRD patterns of the products obtained from different volume ratio of DMF to distilled water.

DMF volume of $25 \mathrm{~mL}, 20 \mathrm{~mL}, 12.5 \mathrm{~mL}, 5 \mathrm{~mL}$ and $0 \mathrm{~mL}$ respectively. There were many nanoparticles-aggregated nanorods when prepared in $25 \mathrm{~mL}$ DMF (Fig. 5a). As shown in Fig. 5c-e, nanobelts-assembled $\mathrm{ZnOHF}$ nanoflowers were obtained when $12.5 \mathrm{~mL} \mathrm{DMF}, 5 \mathrm{~mL} \mathrm{DMF}$ and $0 \mathrm{~mL}$ DMF were used. Comparatively, the dimensions of the nanobeltassembled ZnOHF flowers obtained without DMF (Fig. 5e) is much larger than the former, that is, distilled water will be beneficial to the growth of ZnOHF. On the other hand, the introducing of DMF molecule will increase the opportunity to form ZnO. Therefore, DMF plays a key role in the cake-like microstructures formation, and thus the amount of DMF should be controlled in a proper range.

$$
\begin{gathered}
\mathrm{Zn}^{2+}+\mathrm{DMF} \rightarrow \mathrm{Zn}^{2+}-\mathrm{DMF} \\
\mathrm{BF}_{4}{ }^{-}+3 \mathrm{H}_{2} \mathrm{O} \rightarrow \mathrm{H}_{3} \mathrm{BO}_{3}+3 \mathrm{HF}+\mathrm{F}^{-} \\
\mathrm{Zn}^{2+}-\mathrm{DMF}+\mathrm{F}^{-} \leftrightarrow \mathrm{ZnF}^{+}+\mathrm{DMF} \\
\mathrm{DMF}+2 \mathrm{H}_{2} \mathrm{O} \leftrightarrow \mathrm{DMF} \cdot \mathrm{H}_{3} \mathrm{O}^{+}+\mathrm{OH}^{-} \\
\mathrm{ZnF}^{+}+\mathrm{OH}^{-} \leftrightarrow \mathrm{ZnOHF} \\
\mathrm{ZnF}^{+}+2 \mathrm{OH}^{-} \leftrightarrow \mathrm{ZnO}+\mathrm{H}_{2} \mathrm{O}+\mathrm{F}^{-}
\end{gathered}
$$

As we all know, as a solvent, the addition of DMF can change the properties of the reaction system including the polarity, viscosity, surface tension, boiling point, etc. Therefore, the formation of different type of products ( $\mathrm{ZnO} \& \mathrm{ZnOHF}$ ) with different morphologies is owing to the combined effects of water and DMF under the solvothermal conditions. After suitable amount of DMF being introduced which acting as a Lewis base, its $\mathrm{N}$ atoms in amido groups will react with the $\mathrm{HF}$ molecules in ZnOHF, thus, an acid-base neutralization occurred, consequently, ZnO will be formed. Secondly, as surface-functionalizing agent, owing to the coordinate activities of $\mathrm{O}$ and $\mathrm{N}$ atoms in DMF molecules could react with $\mathrm{Zn}^{2+}$ ions

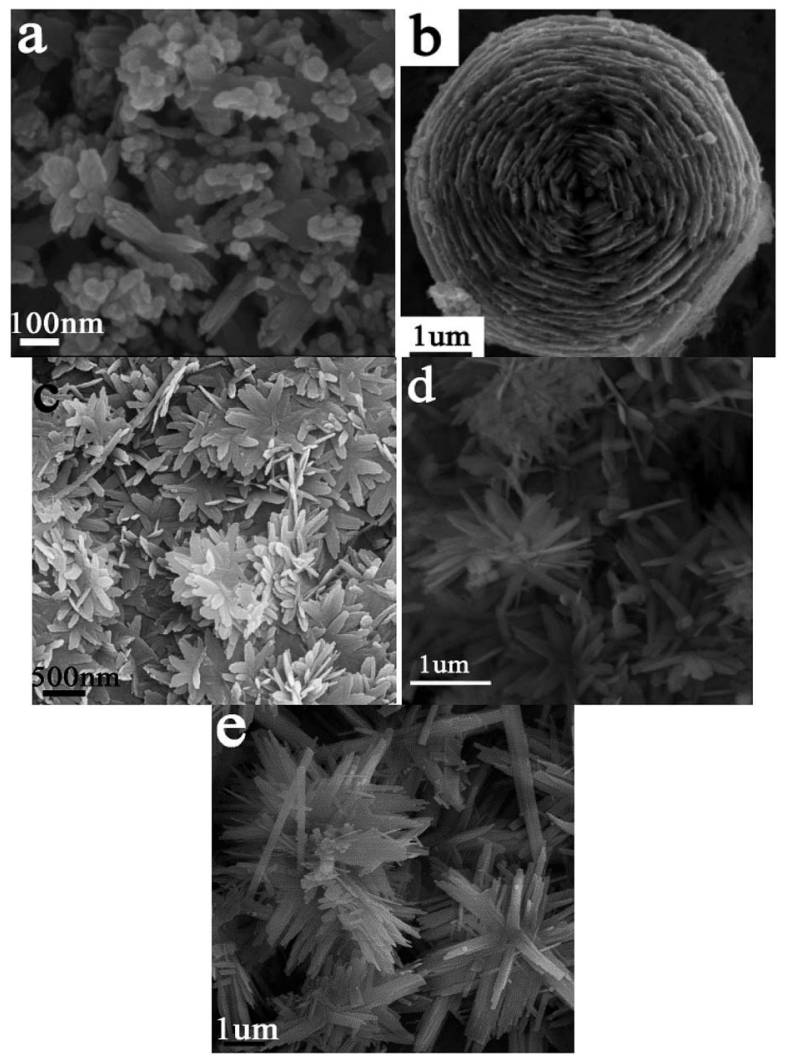

Fig. 5 SEM images of the products obtained from different volume of DMF: (a) $25 \mathrm{~mL}$, (b) $20 \mathrm{~mL}$, (c) $12.5 \mathrm{~mL}$, (d) $5 \mathrm{~mL}$ and (e) $0 \mathrm{~mL}$.

to form $\mathrm{Zn}^{2+}$-DMF complexes c. As well known, the hydrolysis process of $\mathrm{BF}_{4}{ }^{-}$to produce $\mathrm{F}^{-}$is very slow, which keeps the low concentration of $\mathrm{F}^{-}$in the solution (eqn (2)). ${ }^{27-29}$ With the introduction of $\mathrm{BF}_{4}{ }^{-}, \mathrm{Zn}^{2+}$ can be continuously supplied by gradual dissociation of the $\mathrm{Zn}^{2+}$-DMF complexes and will react with $\mathrm{F}^{-}$to form intermediates $\mathrm{ZnF}^{+}$(eqn (3)). Then, ZnOHF obtained from a small quantity of DMF, while $\mathrm{ZnO}$ formed from a large quantity of DMF (eqn (4)-(6)). The adsorption and desorption of DMF molecules on different surfaces of the growing $\mathrm{ZnO}$ or $\mathrm{ZnOHF}$ nuclei may kinetically control the growth rates along different crystal directions. Although we do not quietly understand its exact function, it is clear that DMF is of great importance for obtaining different products with different morphologies. The proper amount of DMF might be favorable to the formation of hierarchical nanoplatesassembled cake-like $\mathrm{ZnO}$ or nanobelts-assembled flower-like ZnOHF architectures.

To better understand the formation process of such a hierarchical structure, experiments with different amounts of $\mathrm{NH}_{4} \mathrm{BF}_{4}$ were conducted, which indicated that the $\mathrm{NH}_{4} \mathrm{BF}_{4}$ amount was crucial in controlling the morphology of the products. When $20 \mathrm{~mL}$ DMF and $5 \mathrm{~mL}$ water were used, keeping other reaction conditions unchanged, the crystalline phases and microstructures of the products obtained at the amount of $\mathrm{NH}_{4} \mathrm{BF}_{4}$ as 0.8 and $1.0 \mathrm{mmol}$ were studied by XRD and SEM. As shown in Fig. 6A, the XRD patterns of the as-obtained samples are indexed as pure hexagonal phase of ZnO (JCPDS card no. 36- 

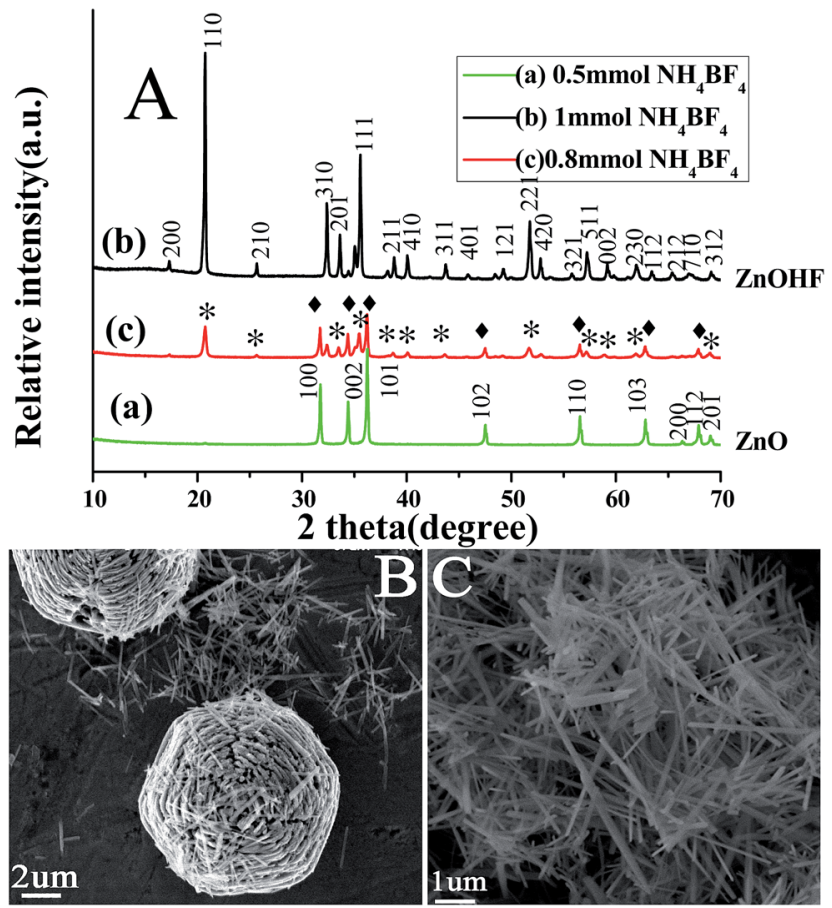

Fig. 6 XRD patterns ( $A$ ) and SEM images ( $B$ and $C$ ) of the products obtained from different amount of $\mathrm{NH}_{4} \mathrm{BF}_{4}(*, \bullet$ denoted as $\mathrm{ZnO}$ and $\mathrm{ZnOHF)}$

1451) and orthorhombic phase of ZnOHF (JCPDS card no. 741816) when $0.5 \mathrm{mmol}$ and $1 \mathrm{mmol} \mathrm{NH}_{4} \mathrm{BF}_{4}$ were used in the reaction, respectively. However, the mixture of $\mathrm{ZnO}$ and $\mathrm{ZnOHF}$ was formed when $0.8 \mathrm{mmol} \mathrm{NH}_{4} \mathrm{BF}_{4}$ introduced. Fig. $6 \mathrm{~B}$ and $\mathrm{C}$ show the corresponding SEM images of the products obtained from $0.8 \mathrm{mmol}$ and $1 \mathrm{mmol} \mathrm{NH}_{4} \mathrm{BF}_{4}$. As the amount of $\mathrm{NH}_{4} \mathrm{BF}_{4}$ was fixed at $0.8 \mathrm{mmol}$, two kinds of morphologies, hierarchical cake-like architectures and nanowires were co-existent in the reaction (Fig. 6B). The morphologies of the $\mathrm{ZnOHF}$ prepared from $1 \mathrm{mmol} \mathrm{NH}_{4} \mathrm{BF}_{4}$ are nanowires with the length up to several micrometers (Fig. 6C). From the chemical reaction presented by eqn (2) and (6), it is obvious that, at higher amount of $\mathrm{NH}_{4} \mathrm{BF}_{4}$, the reverse reaction is favored which can dissolve the $\mathrm{ZnO}$ phase and result in the formation of $\mathrm{ZnOHF}$ phase. Therefore, massive $\mathrm{NH}_{4} \mathrm{BF}_{4}$ is in favor of the formation of the $\mathrm{ZnOHF}$, which is consistent with our previous work. ${ }^{30}$ As described above, $\mathrm{ZnO}$ and $\mathrm{ZnOHF}$ could be selectively prepared by simply controlling the amount of $\mathrm{NH}_{4} \mathrm{BF}_{4}$ in this procedure.

\section{Evolution of morphology and growth mechanism}

To further understand the formation mechanism of the hierarchical cake-like $\mathrm{ZnO}$ architectures, the time-dependent morphological evolution through interception of the intermediate products was performed at different reaction stage. As mentioned in the XRD results (Fig. 1), the size or the crystallinity of the products increases with prolonging the reaction time from $3 \mathrm{~h}$ to $24 \mathrm{~h}$. Fig. 7a-c show the corresponding SEM images of the products obtained within $3 \mathrm{~h}, 6 \mathrm{~h}, 12 \mathrm{~h}$ in $0.5 \mathrm{mmol} \mathrm{NH}_{4} \mathrm{BF}_{4}$ in the presence of $20 \mathrm{~mL} \mathrm{DMF} / 5 \mathrm{~mL}$ water.

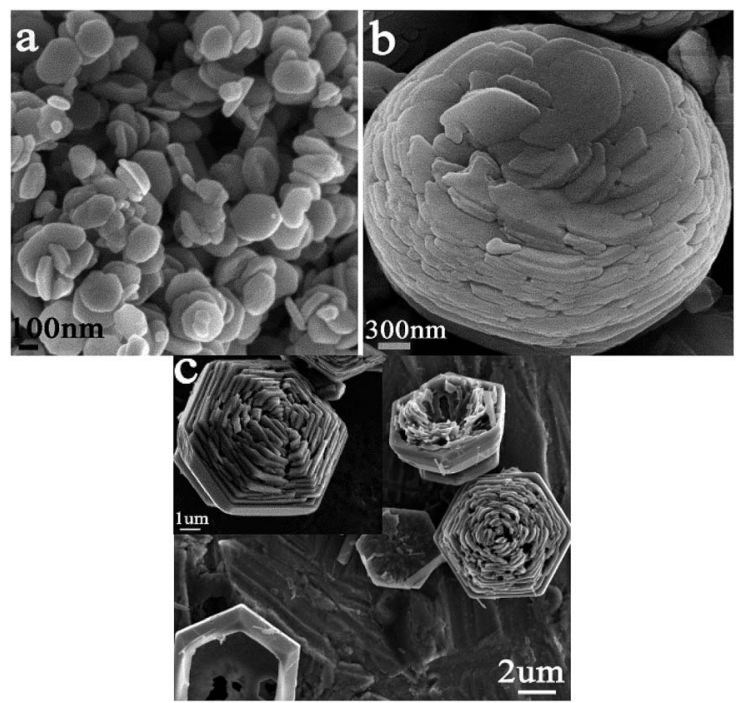

Fig. 7 SEM images of the $\mathrm{ZnO}$ obtained from different reaction time: (a) $3 \mathrm{~h},(\mathrm{~b}) 6 \mathrm{~h},(\mathrm{c}) 12 \mathrm{~h}$.

Many irregular nanoplates with thickness about $50 \mathrm{~nm}$ were formed after reaction for $3 \mathrm{~h}$, as shown in Fig. 7a. With a prolongation of the reaction time to $6 \mathrm{~h}$, the as-obtained samples are persimmon-shaped architectures with a concave dip in the center, which were constructed by a large amount of layer-by-layer assembled nanoplates (Fig. 7b). Further prolonging reaction time to $12 \mathrm{~h}$, as shown in Fig. 7c, the SEM images reveal that the sample is a hierarchical hexagonal cake-like structure with nanoplates ordered stacking. As the assembled building unit, the nanoplate is thinner than $50 \mathrm{~nm}$, which is consistent with the size of the products obtained from $3 \mathrm{~h}$. Interestingly, the shape stability of the hierarchical cakes were investigated by ultrasonic irradiation at $300 \mathrm{~W}$ for $1 \mathrm{~h}$. Consequently, the stacking nanoplates were collapsed from the bottom of the cakes. Therefore, the fascinating hierarchical hexagonal 3D cake-like architectures are constructed by two parts, the outer is a hexagonal bowl-like structure and the inner is layer-by-layer nanoplates. These above results indicate that the morphologies of the $\mathrm{ZnO}$ are dependent on the reaction time. With the increasing of reaction time, there is a selfassembly induced morphological evolution process from $2 \mathrm{D}$ nanoplates, hierarchical persimmon-shaped microstructures into 3D hierarchical cake-like architectures.

As described above, we have systematically investigated the growth of hierarchical cake-like $\mathrm{ZnO}$ microstructure by changing experimental conditions. A possible formation mechanism was proposed based on the time-dependent morphological evolution results, as shown in scheme 1. Initially, $\mathrm{Zn}^{2+}$ and a proper amount of DMF coordinate to form some $\mathrm{Zn}^{2+}$-DMF complexes. Then $\mathrm{BF}_{4}{ }^{-}$ions react with the $\mathrm{Zn}^{2+}$ ions (released from the $\mathrm{Zn}^{2+}$-DMF complexes) to produce $\mathrm{ZnO}$ nanoparticles. Secondly, the tiny $\mathrm{ZnO}$ nanoparticles grow up into nanoplates, as shown in Fig. 7a. In the third step, with increasing the reaction time, the $\mathrm{ZnO}$ nanoplates aggregate and self-assembled into persimmon-shaped architectures (Fig. 7b). In the fourth step, with the persimmon-shaped architectures 


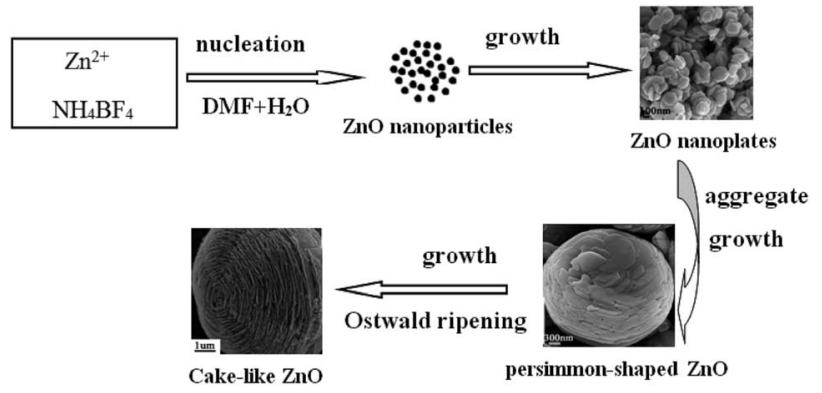

Scheme 1 Illustration of the growth process of hierarchical cake-like $\mathrm{ZnO}$ microstructures.

further growing and growing, layer-by-layer nanoplates assembled hexagonal bowl-like structures are formed through the Ostwald ripening process (Fig. 7c). Finally, hexagonal bowl evolves to round bowel during the ripening process and the hierarchical cake-like architectures are obtained. Therefore, the self-assembly and Ostwald ripening are the main formation mechanism for the formation of hierarchical cake-like $\mathrm{ZnO}$ architecture.

\section{Photocatalytic properties}

The photocatalytic activity of $\mathrm{ZnO}$ micro/nanostructures with different morphologies was assessed by investigating the photodegradation of RhB aqueous solution under UV light irradiation. Fig. 8a shows the temporal evolution of the absorption spectra during the photocatalytic degradation of $\mathrm{RhB}$ in the presence of hierarchical cake-like $\mathrm{ZnO}$ microstructures. The characteristic absorption of $\mathrm{RhB}$ at $553 \mathrm{~nm}$ was used to monitor the degradation process as a function of irradiation time.

With the extension of the exposure time, the absorption intensity decreased rapidly and almost disappeared after 20 min. As shown in Fig. 8b, the degradation efficiency of RhB as a function of irradiation time using different morphological ZnO photocatalysts, where $C_{0}$ is the absorption of RhB aqueous solution before UV irradiation and $C$ is its absorption after definite illumination time. It is found that the degradation of $\mathrm{RhB}$ was very slow in the absence of the photocatalysts (blank test). Whereas, the significant decrease of RhB concentration was observed under UV light via using cake-like ZnO powders, indicating the hierarchical cake-like $\mathrm{ZnO}$ architectures exhibited excellent photocatalytic performance. The degradation process is fitted to pseudo-first-order kinetics, and the values of the $k_{\text {app }}$ are shown in Fig. $8 \mathrm{c}$ respectively. Generally, the size, crystallinity, morphology and surface areas of photocatalysts have important effects on the photocatalytic activity. ${ }^{31-33}$ The higher specific surface area resulting in much more surface contact probability to pollutants, greatly improves the efficiency of photocatalytic degradation of the organic materials. Compared with that of nanoplates-assembled hierarchical ZnO $\left(113.896 \mathrm{~m}^{2} \mathrm{~g}^{-1}\right)$, the $\mathrm{ZnO}$ nanoplates have a lower specific surface-area as $34.578 \mathrm{~m}^{2} \mathrm{~g}^{-1}$. Therefore, the activity of $\mathrm{ZnO}$ nanoplates is less than hierarchical cake-like $\mathrm{ZnO}$ in photocatalytic degradation of $\mathrm{RhB}$, which may be attributed to its
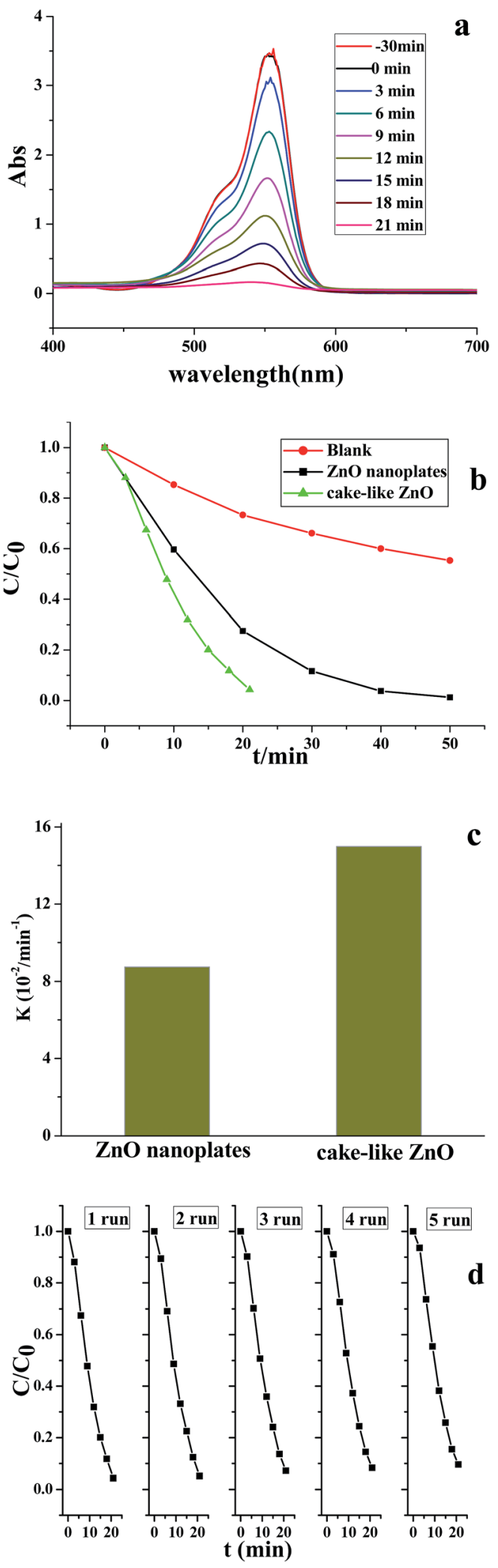

Fig. 8 (a) UV-vis absorption spectra of RhB under UV light irradiation $(365 \mathrm{~nm})$ for different times with hierarchical cake-like $\mathrm{ZnO}$ microstructures; (b) the photodegradation efficiencies of RhB as a function of irradiation time under UV light; (c) $k_{\text {app }}$ values of samples under UV light and (d) the cycle test of hierarchical cake-like ZnO microstructures. 


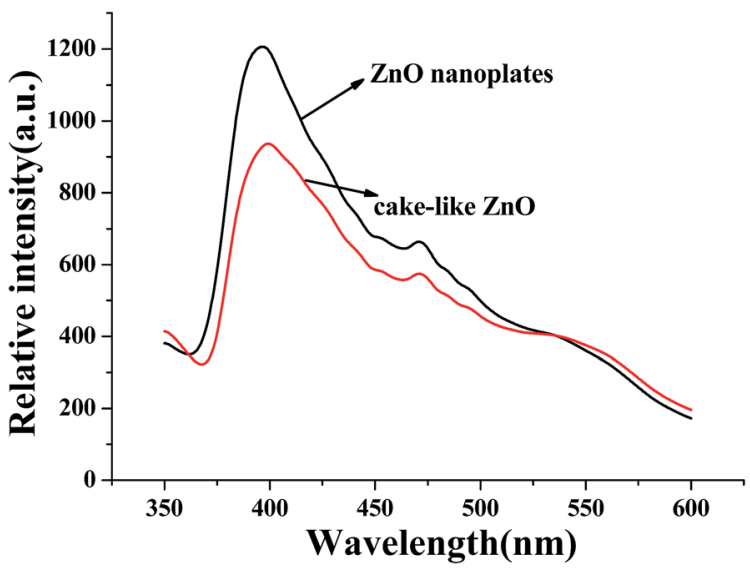

Fig. 9 PL spectra of the as-obtained samples at room temperature.

good crystallinity and larger surface area. To examine the photocatalytic stability and recyclable ability of the catalysts, the efficiency of the RhB photodegradation was determined with a repetitive mode by collecting the photocatalyst in the reaction solution and repeating the photocatalyst is assessment. Fig. 8d shows the cycle tests of hierarchical cake-like ZnO microstructures under UV light irradiation, the efficiency remained almost the same after five runs, confirming the hierarchical $\mathrm{ZnO}$ are chemically stable. Therefore, the hierarchical cake-like $\mathrm{ZnO}$ can be a promising UV light photocatalyst for practical applications.

\section{Photoluminescence properties}

Different mechanisms of photocatalytic dye degradation have been proposed, it is commonly accepted that the separation efficiency of photoinduced electron-hole pairs is the key factor in the photocatalytic process. ${ }^{34,35}$ It is known that the PL spectrum provides information about recombination of photoinduced carriers. ${ }^{36,37}$ The PL spectra of the hierarchical cakelike $\mathrm{ZnO}$ and $\mathrm{ZnO}$ nanoplates are shown in Fig. 9. It shows the representative PL spectra of the two samples with the excitation wavelength of $325 \mathrm{~nm}$ at room temperature. The emission at around $395 \mathrm{~nm}$ was observed, which is due to radiative recombination of free excitions. Generally, the higher PL intensity suggests easier recombination of electrons and holes. Herein, compared to ZnO nanoplates, the hierarchical cake-like ZnO exhibited relatively low PL intensity, confirming the spatial separation of photo-induced electron-holes. Therefore, the photocatalytic activity of hierarchical cake-like $\mathrm{ZnO}$ is much higher than $\mathrm{ZnO}$ nanoplates in the degradation of $\mathrm{RhB}$, which is consistent with the photocatalytic results.

\section{Conclusions}

Using DMF and water as solvents, 3D hierarchical nanoplatesassembled cakelike $\mathrm{ZnO}$ microstructures are synthesized via a facile, cost-effective and template-free solvothermal route. The reaction parameters such as the reaction time, the amount of fluoride source and the ratio of DMF/water play crucial roles in the formation of hierarchical cake-like ZnO. Owning to the special hierarchical architecture with a high specific surface area, the hierarchical cake-like $\mathrm{ZnO}$ exhibit excellent photocatalytic activity and chemical cycle ability for the degradation of RhB under UV light, which are favorable for its application in catalysis fields.

\section{Acknowledgements}

This work was supported by National Natural Science Foundation of China (No. 21501100, 21376124, 51501088), SRF for ROCS SEM (2014-1685), the Fundamental Research Funds for the Central Universities (No. 021314380019) and Nantong Applied and Basic Research Project (No. GY12015003).

\section{References}

1 M. Wang, T. M. Sun, Y. J. Shi, G. Q. Jiang and Y. F. Tang, CrystEngComm, 2014, 16, 10624-10630.

2 M. Wang, G. Q. Jiang, Y. F. Tang and Y. J. Shi, CrystEngComm, 2013, 15, 1001-1006.

3 Y. Zhang, J. Q. Xu, Q. Xiang, H. Li, Q. Y. Pan and P. C. Xu, J. Phys. Chem. C, 2009, 113, 3430-3435.

4 H. K. Wang and A. L. Rogach, Chem. Mater., 2014, 26, 123133.

5 T. M. Sun, M. Wang, Y. F. Tang, J. J. Ding and Y. J. Zhang, Mater. Lett., 2016, 177, 120-123.

6 F. F. Tao, C. L. Gao, Z. H. Wen, Q. Wang, J. H. Li and Z. Xu, J. Solid State Chem., 2009, 182, 1055-1060.

7 Z. Chen and M. H. Cao, Mater. Res. Bull., 2011, 46, 555-562.

8 F. Lu, W. P. Cai and Y. G. Zhang, Adv. Funct. Mater., 2008, 18, 1047-1056.

9 D. C. Reynolds, D. C. Loo and B. Jogai, Phys. Rev. B: Condens. Matter Mater. Phys., 1999, 60, 2340-2344.

10 Y. F. Chen, D. M. Bagnall, H. J. Koh, K. T. Park, K. Hiraga, Z. Q. Zhu and T. Yao, J. Appl. Phys., 1998, 84, 3912-3918.

11 X. C. Wang, J. C. Yu, C. M. Ho, Y. D. Hou and X. Z. Fu, Langmuir, 2005, 21, 2552-2559.

12 L. R. Hou, H. Hua, L. K. Gan and C. Z. Yuan, Mater. Lett., 2015, 159, 35-38.

13 W. Q. Cai, J. G. Yu and M. Jaroniec, J. Mater. Chem., 2010, 20, 4587-4594.

14 M. Wang, Y. F. Tang, T. M. Sun, G. Q. Jiang and Y. J. Shi, CrystEngComm, 2014, 16, 11035-11041.

15 A. K. Sinha, M. Basu, M. Pradhan, S. Sarkar and T. Pal, Chem.-Eur. J., 2010, 16, 7865-7874.

16 X. Li, J. G. Yu and M. Jaroniec, Chem. Soc. Rev., 2016, 45, 2603-2636.

17 S. Maiti, S. Pal and K. K. Chattopadhyay, CrystEngComm, 2015, 17, 9264-9295.

18 Q. N. Liu, Z. Q. Sun, Y. H. Dou, J. H. Kim and S. X. Dou, J. Mater. Chem. A, 2015, 3, 11688-11699.

19 N. Saito and H. Haneda, Sci. Technol. Adv. Mater., 2011, 12, 064707.

20 Y. Xia, J. Wang, R. S. Chen, D. L. Zhou and L. Xiang, Crystals, 2016, 6, 148.

21 D. W. Wang, S. S. Du, X. Zhou, B. Wang, J. Ma, P. Sun, Y. F. Sun and G. Y. Lu, CrystEngComm, 2013, 15, 7438-7442. 
22 Q. Q. Jia, H. M. Ji, Y. Zhang, Y. L. Chen, X. H. Sun and Z. G. Jin, J. Hazard. Mater., 2014, 276, 262-270.

23 J. Wang, S. C. Hou, L. Z. Zhang, J. C. Chen and L. Xiang, CrystEngComm, 2014, 16, 7115-7123.

24 R. Krishnapriya, S. Praneetha and A. V. Murugan, New J. Chem., 2016, 40, 5080-5089.

25 M. A. Desai and S. D. Sartale, Cryst. Growth Des., 2015, 15, 4813-4820.

26 M. Wang, T. M. Sun, Y. F. Tang, G. Q. Jiang and Y. J. Shi, Mater. Lett., 2015, 160, 150-153.

27 M. Wang, X. L. Shen, G. Q. Jiang and Y. J. Shi, Mater. Lett., 2012, 87, 54-57.

28 M. Wang, Q. L. Huang, H. X. Zhong, X. T. Chen, Z. L. Xue and X. Z. You, Cryst. Growth Des., 2007, 7, 2106-2111.

29 M. Wang, Q. L. Huang, J. M. Hong, X. T. Chen and Z. L. Xue, Cryst. Growth Des., 2006, 6, 1072-1974.
30 Q. L. Huang, M. Wang, H. X. Zhong, X. T. Chen, Z. L. Xue and X. Z. You, Cryst. Growth Des., 2008, 8, 1412-1417.

31 L. Zhang, X. F. Cao, X. T. Chen and Z. L. Xue, J. Colloid Interface Sci., 2011, 354, 630-636.

32 B. Ohtani, F. Amano, A. Yamakata, K. Nogami and M. Osawa, J. Am. Chem. Soc., 2008, 130, 17650-17651.

33 X. Y. Xing, Y. X. Ma, J. Li, G. Y. Fan, H. F. Ding, X. M. Ma, L. Yang and G. X. Xi, CrystEngComm, 2014, 16, 10218-10226.

34 L. A. Gu, J. Y. Wang, H. Cheng, Y. Z. Zhao, L. F. Liu and X. J. Han, ACS Appl. Mater. Interfaces, 2013, 5, 3085-3093.

35 D. M. Chen, Z. H. Wang, T. Z. Ren, H. Ding, W. Q. Yao, R. L. Zong and Y. F. Zhu, J. Phys. Chem. C, 2014, 118, 15300-15307.

36 N. Li, J. Zhang, Y. Tian, J. H. Zhao, J. Zhang and W. Zuo, Chem. Eng. J., 2017, 308, 377-385.

37 Q. L. Huang, Q. T. Zhang, S. S. Yuan, Y. C. Zhang and M. Zhang, Appl. Surf. Sci., 2015, 353, 949-957. 